\title{
Life Cycle Strategies and Physiological Adjustments of Reedfrog Tadpoles (Amphibia, Anura, Hyperoliidae) in Relation to Environmental Conditions
}

\author{
R. Schmuck, W. Geise, and K. E. Linsenmair
}

\begin{abstract}
The relationship between different degrees of intraspecific crowding of reedfrog tadpoles and their physiological responses to a deterioration of the natal pond water quality was examined under laboratory conditions. Tadpoles that were reared at a lower density metamorphosed significantly earlier than those raised at a higher density. As density increases, the average body length at metamorphosis decreases. However, at low tadpole density, a significantly higher diversity of body size classes among freshly metamorphosed froglets was observed than under more crowded conditions. Mortality increased during metamorphic climax and was inversely correlated with the tadpole density.

In ephemeral ponds, an accumulation of nitrogenous wastes from metabolic processes and/or a concentration by evaporation in prolonged rainless periods can pose a considerable chemical stress to reedfrog tadpoles. Hyperolius viridiflavus ommatostictus responded to an increasing ammonia concentration with an activity increase of the ornithine cycle (intensified urea synthesis). In contrast, Hyperolius marmoratus taeniatus exhibited a strong tolerance against high ammonia levels.

A deterioration of the natal pond water quality caused $H$. $v$. ommatostictus and H. $v$. nitidulus tadpoles to adjust to harsher climatic conditions at the time of metamorphosis. This physiological preadjustment enabled the froglets to start feeding and growing immediately after metamorphosis even at low air humidity and rare precipitation events. In contrast, froglets that were raised in daily refreshed water exhibited high mortality rates if subjected to identical conditions. As one possible indicator of the actual climatic conditions prevailing in the surrounding terrestrial habitat, fluctuations in the water ammonia level are discussed.
\end{abstract}

A lthough anürans successfully invaded semiarid and even arid habitats, they generally did not alter their characteristic biphasic mode of life (Duellmann and Trueb, 1986) which is viewed as an adaptation for exploiting the high, but only transient, productivity of temporary ponds (Wilbur and Collins, 1973; Wassersug, 1975; Wilbur, 1980). In xeric habitats, anurans have to deal with strongly fluctuating and often unpredictably changing conditions both in the aquatic and in the terrestrial habitat. The evolution of adaptive variations of their life cycles may be an appropriate way to cope with those environmental conditions. Within the range of physiologically constrained rates of differentiation (Smith-Gill and Berven, 1979), the resulting life cycle strategies should, therefore, reflect a trade-off between risks and benefits provided by the anticipated future conditions of the aquatic habitat, the size-related risks at the switch between the aquatic and the terrestrial habitats (susceptibility to predators is expected to change with the body size at metamorphosis), and the risks and benefits provided by the conditions that prevail in the terrestrial habitat during the initial time after metamorphosis.

In temporary ponds used by West African savannah-inhabiting frogs, intra- and interspecific competition, predation, and, in particular, the deterioration of the water quality up to desiccation appear to be the main restricting factors in the tadpoles' success (KEL, unpubl.). During the switch to the terrestrial habitat, predation is thought to represent a main risk (Werner, 1986). In the terrestrial environment, desiccation is also considered a major challenge and the more so the smaller the metamorphosed froglets are. The length of the larval period and the size at metamorphosis are variables that will be determined by these and additional factors (Brockelman, 1969; Low, 1976; Berven and Chadra, 1988).

The study subjects, Hyperolius viridiflavus ommatostictus, Hyperolius viridiflavus nitidulus, and Hyperolius marmoratus taeniatus, are common in African savannahs which are characterized by marked wet and dry periods (Schiotz, 1967). 
Juveniles have developed a series of spectacular physiological adaptations which allow them to survive even under the especially demanding conditions of the strongly and rather unpredictably fluctuating savannah habitats (Geise and Linsenmair, 1988; Kobelt and Linsenmair, 1992; Schmuck et al., 1988). These Hyperolius species start spawning during periods of high precipitation and continue until well into the transitional season which is usually characterized by, at most, very casual and light rain but generally a regular nightly dewfall (assumed for H. v. ommatostictus, H. m. taeniatus from their laboratory behavior, and for the West African species $H$. v. nitidulus from ample direct observations in four years; KEL, unpubl.). Throughout the larval period, temporal and qualitative stability of the natal ponds is quite unpredictable. Moreover, temporary ponds often exhibit unusually high tadpole densities, which may dramatically increase with the evaporative reduction of the water volume. The consequences of this becomes intensified intra- and interspecific competition as well as an increased exposure to some important predators. These factors might pose selective pressures favoring a rapid completion of the larval period. In the present paper, we investigated, among others, the relationship between different degrees of intraspecific crowding of Hyperolius tadpoles and the resulting metamorphic strategies (i.e., length of larval period, body size at metamorphosis).

The deterioration of the abiotic quality of ephemeral ponds may pose further constraints on the aquatic life stage. To successfully exploit habitats with unpredictably fluctuating abiotic conditions, the inhabitants must have developed either extreme tolerances or highly developed physiological mechanisms to maintain their homeostasis. Until now, little attention has been paid to the nitrogenous wastes which in smaller ponds may accumulate to lethal concentrations before evaporation becomes the critical factor. Ammonia is the main nitrogenous waste product of most aquatic organisms; and, because of its high cell toxicity (Hochachka and Somero, 1980), it could play an important role as a limiting factor in ephemeral ponds. Therefore, we addressed the physiological responses to a deterioration of the pond water quality by investigating the tadpoles' responses to an accumulation/concentration of nitrogenous wastes resulting from crowding effects and/or water shortage resulting from evaporation.

Geise (1987) demonstrated that Hyperolius froglets need to have a minimum body length/ volume ratio and sufficient energy reserves to survive the harsh climatic conditions prevailing during the dry season. Most froglets that metamorphosed under uniform favorable laboratory conditions (ad libitum food supply, high pond water quality, low tadpole density) or that have been observed in the field (KEL, unpubl. obs.) did not have these required threshold body size or fat reserves. Therefore, most froglets have to feed and grow extensively in the terrestrial habitat before the onset of the dry season. Since late tadpoles of Hyperolius species may already, and in $H . v$. nitidulus definitely do, experience harsh climatic conditions at or shortly after metamorphosis, they would greatly benefit from an appropriate physiological adjustment at metamorphosis. An appropriate adaptation would allow them to forage still for a prolonged time during the initial phase of the dry period with already high thermal and drought stress during daytime while water availability is restricted to dewfall at night which becomes more and more irregular with progressing dry period. Changes in the climatic conditions influence both the physical and chemical conditions in small bodies of water. These changes could provide signals to the tadpoles which may serve as indicators of the climatic conditions to be anticipated in the terrestrial habitat at metamorphosis and which may direct alternative developmental routes. In the present study, we examined whether the deterioration of the natal pond quality (e.g., accumulation of nitrogenous wastes) affects the physiological adjustment (dry or wet adapted) of the metamorphosing froglets.

\section{Materials and Methods}

Juveniles of $H . m$. taeniatus were collected within a $50-\mathrm{km}$ radius of Maputo, Mosambique. Experiments were performed on the F1 generation of these specimens. Hyperolius viridiflavus ommatostictus juveniles were purchased from a commercial breeder. The experiments were performed on the F2 generation of these specimens. Hyperolius viridiflavus nitidulus is common in West African savannah areas. Field observations were mainly performed in the Comoe' National Park in northeastern Ivory Coast. Laboratory experiments were done with newly fieldcollected specimens and the F1 and F2 laboratory-bred generation.

Growth pattern and energy allocation under favorable growth conditions.-Fifty tadpoles (beginning with stage 23; Gosner, 1960) of the reedfrog $H . m$. taeniatus were raised to metamorphosis at $28 \pm 2 \mathrm{C}$ and $13 / 11 \mathrm{~h} \mathrm{~L} / \mathrm{D}$ 
cycle in three aquaria $(40 \times 25$ and $25 \mathrm{~cm}$ deep $)$, each filled with 10 liters of tap water (five tadpoles/liter). The tadpoles were fed on commercial fish food (Tetrawerke, Melle) and fresh lettuce and received further nutrients from spontaneously growing algae. In this way, a diversified and abundant food supply was ensured. Every fourth day, three animals were randomly removed from each aquarium (a fish net was drawn once through the length of the aquarium, and the first three larvae netted were used for the measurement). The stage of development and body length of these tadpoles were recorded. The body length was determined with a caliper rule from the tip of the head to the opening of the vent with $0.1 \mathrm{~mm}$ accuracy. After metainorphosis, froglets were sacrificed. The abdominal fat pads were removed and weighed. The remaining carcasses were dried at $60 \mathrm{C}$ to a constant mass and the remaining body lipid content determined according to the method of Beurden (1980). Removed or dead tadpoles were not replaced during the experiment.

Metamorphic strategies and energy allocation at different tadpole densities.- The effect of tadpole density on the length of the larval period and body length of $H$. m. taeniatus at metamorphosis was examined by raising 20 tadpoles [beginning at stage 23; four tadpoles/liter = low density (LD); three replicates] and 60 [ 12 tadpoles/ liter $=$ high density (HD); two replicates $]$ in small aquaria (20 $\times 25$ and $25 \mathrm{~cm}$ deep), each filled with 5 liters of tap water to metamorphosis. Larvae were obtained randomly from five egg batches to equalize possible genetic variations between different clutches. The animals were fed ad libitum under the same temperature and light conditions as in the first experiment. The time of and the body size at metamorphosis were recorded for both groups.

Because of the low mortality until stage 42 (less than $15 \%$ in both groups), none of the dead or removed animals was replaced during the experiment. Also animals that died shortly prior to metamorphosis (after stage 42 the mortality rate increased sharply) or those that completed metamorphosis were not replaced.

The water within the aquaria was changed every second or third day at low density and every one or two days at high densities, depending upon the ammonia concentration which was monitored daily with a colorimetric test kit (Fa. Merck). In this way, the average ammonia concentration was comparable in both groups, and a deterioration of the water quality resulting from an accumulation of nitrogenous wastes could mostly be excluded as a decisive factor influencing the time of metamorphosis. With this water-changing schedule, the ammonia concentration averaged $2.0 \pm 0.7 \mathrm{mg} \mathrm{NH}_{4}{ }^{+}$ $-\mathrm{N}$ /liter with a range of $0.7-2.9 \mathrm{mg} \mathrm{NH}_{4}{ }^{+}$ $-\mathrm{N} /$ liter. Immediately after leaving the water, froglets were measured to the nearest $0.1 \mathrm{~mm}$ with a micrometer caliper rule and weighed. A subgroup of 30 individuals of both density groups was analyzed for lipid content, as described above.

Nitrogen excretion pattern in relation to the ambient ammonia concentration.-Ephemeral ponds in West Africa inhabited by different amphibian species had ammonia concentrations that temporarily exceeded $20 \mathrm{mg} \mathrm{NH}_{4}{ }^{+}-\mathrm{N} /$ liter (KEL, unpubl.). These concentrations were rapidly achieved during dry weather periods (KEL, unpubl.). Such high concentrations should pose a strong chemical stress on the exposed tadpoles which may counteract an intracellular increase of the ammonia concentration by urea synthesis. Because data from ponds inhabited by the investigated species were not available, at that time, we monitored, in Germany, changes in ammonia concentration of a small natural pond (about $2 \times 2 \mathrm{~m}$ and $20 \mathrm{~cm}$ deep) formed by summer rains which contained a large number of bufonid (Bufo bufo) larvae (more than 15 larvae/liter) during an exceptionally hot summer period in 1987. At the beginning and the end of a precipitation-free period of four weeks, water samples from this pond were analyzed for their ammonia concentration. In addition to the water analysis, samples of 10 larvae from stage 30 and stage 40 were also removed. After rinsing with tap water, three groups of larvae (number of tadpoles per test group was equivalent to $2.0 \pm 0.35 \mathrm{~g}$ body fresh mass) of both stages were transferred to $20 \mathrm{ml}$ distilled water which was analyzed 24 hours later for its urea content (Sigma diagnostic kit). The detection limit was $0.3 \mathrm{micro}$ Mole $/ \mathrm{g}$ body mass. To prevent microbial degradation of urea during the experimental phase, some chloramphenicol had been added to the test water shortly before starting the experiment. In preliminary studies, it was found that this treatment was not toxic and did not affect the development of the tadpoles. In addition, three $B$. bufo tadpoles originating from the almost dried up natal pond were directly tested for hepatic arginase activity (according to Schmuck and Linsenmair, 1988).

In the same fashion, tadpoles from stages 30 44 of $H$. m. taeniatus and $H$. v. ommatostictus were examined that had been raised in groups of 150 animals per aquarium, each containing 10 liters 
of tap water at $24 \pm 2 \mathrm{C}$ and a $12.5 / 11.5 \mathrm{~L} / \mathrm{D}$ cycle. The larvae had been fed ad libitum. In group 1, water was replaced completely with fresh water every 24 hours which kept the ammonia concentration constantly below $1 \mathrm{mg}$ $\mathrm{NH}_{4}{ }^{+}-\mathrm{N} /$ liter most of the time. In group 2, only one-quarter of the water was replaced following the same time schedule as for group 1 (= complete change every fourth day). The ambient ammonia concentration of group 2 fluctuated around $5 \mathrm{mg} \mathrm{NH}{ }_{4}^{+}-\mathrm{N} /$ liter (3.7-5.72 $\mathrm{mg} \mathrm{NH}_{4}{ }^{+}-\mathrm{N} /$ liter). The replacement water had been adjusted to room temperature before use. In both groups, all tadpoles were carefully removed from the aquaria shortly before replacing the water. This procedure was assumed to keep tadpoles of both groups at a comparable stress level.

In a further experiment, two groups of five H. v. ommatostictus tadpoles (from stage $30=$ group 1 and stage $42=$ group 2) were maintained for two days in $25 \mathrm{ml}$ tap water into which $5 \mathrm{mg} \mathrm{NH}+-\mathrm{N} /$ liter had been added. Two control groups from the same natal container were simultaneously reared in $25 \mathrm{ml}$ ammoniafree tap water. The exposure was performed under semistatic test conditions changing the water twice per day. At the end of the second day, tadpoles were tested for urea excretion as outlined for Bufo tadpoles.

Effect of water deterioration on the physiological adjustment at metamorphosis.-As a response to a deterioration of the pond water quality, larvae in metamorphic climax might adjust their physiological state to those climatic conditions actually prevailing in their terrestrial habitat or to those anticipated in the near future. The ammonia concentration in the ambient water was assumed to be a representative indicator of the pond water quality. Eight different $H . v$. ommatostictus egg batches (about 150 eggs/batch) were transferred to glass aquaria $(40 \times 25 \mathrm{~cm}$ and $25 \mathrm{~cm}$ deep), each filled with 10 liters of tap water (= 15 larvae per liter). Rearing conditions were identical to those described in the preceding chapter. In treatment group A (groups 1 and 2), approximately one-third of the rearing water was replaced with fresh water each second or third day and completely changed each day or each second day in treatment group $B_{1}$ (groups 3-8), depending upon the ammonia concentration which was monitored daily with a colorimetric test kit (Fa. Merck). The water exchange procedure was as outlined above. In this way, the ammonia concentration could be kept continuously well above $3 \mathrm{mg} \mathrm{NH}_{4}{ }^{+}-\mathrm{N} /$ liter in groups 1 and 2 and did not exceed $1 \mathrm{mg} \mathrm{NH}{ }_{4}{ }^{+}-\mathrm{N} /$ liter most of the time in groups $3-8$. After tadpole density decreased to approximately $50 \%$ of the original density resulting from metamorphosis, the frequency of water change in groups 3-8 was adjusted to the same schedule as for groups 1 and 2 , causing an increase of the ammonia concentration above $3 \mathrm{mg} \mathrm{NH}_{4}{ }^{+}-\mathrm{N} /$ liter.

From each treatment group, the first 160 froglets that completed the metamorphosis were sampled and placed in subgroups of 80 individuals into loam-filled, planted terraria $(80 \times 55$ $\mathrm{cm}$ and $45 \mathrm{~cm}$ deep $=200$ liters) under conditions simulating the transition period from the wet to the dry season: at a 12-hour daylight regime, temperatures fluctuated between 26 and $33 \mathrm{C}$ during the day and between 22 and $26 \mathrm{C}$ during the night. Relative humidity ranged between $65 \%$ and $100 \%$ during the night and early in the morning and fluctuated around $50 \%$ in the middle of the day. Each second or third day, the terraria were sprayed before artificial sunset corresponding to dewfall under natural conditions during the transitional period (KEL, unpubl.) and the froglets provided ad libitum with fruit flies (Drosophila melanogaster) and house flies (Musca domestica) dusted with vitamins. After spraying, water droplets persisted for about one hour. Survival rates and resting behavior of the animals were recorded as criteria for their physiological adjustments to climatic conditions.

\section{Results}

Growth pattern and energy allocation under favorable growth conditions.-The growth history of the larval stages of $H$. m. taeniatus from the stage of active feeding (stage 23) until metamorphosis is presented in Figure 1 A. Below a body length of $10-11 \mathrm{~mm}$, body mass increased disproportionally faster (allometrically) than body length. During metamorphic climax, body length and body mass increased at almost identical rates (isometric growth). Throughout larval development, overall fat content of tadpoles increased almost continuously (Fig. 1B). Only the strong increase in muscle mass at the end of prometamorphosis caused a decrease of the percent lipid content; however, the absolute proportion remained constant or increased slightly. Abdominal fat bodies, which are generally considered the main energy stores, appeared during the transition from allometric to isometric growth patterns. In Figure 2, the range of potential body sizes at metamorphosis is shown. This spectrum comprises of 140 animals kept in the laboratory under various maintenance 


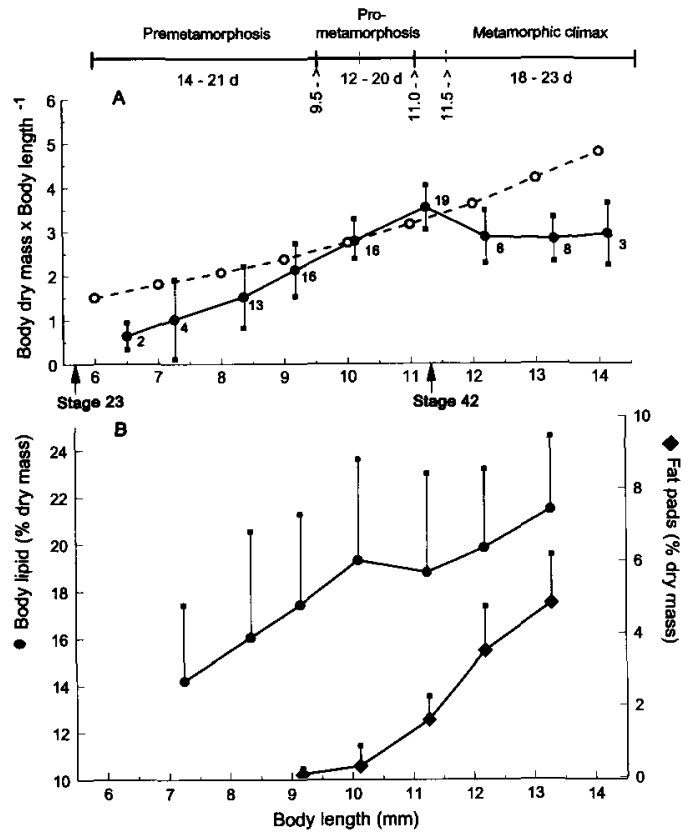

Fig. 1. Growth pattern (increase of body mass vs body length) of Hyperolius marmoratus taeniatus tadpoles raised under favorable growth conditions (five tadpoles/liter, fed ad libitum). Growth history is presented from stage 23 (onset of active food uptake) until metamorphosis (stage $44 / 45$ according to Gosner, 1960). The maximal length of a definite developmental stage is indicated by a dashed line in the top developmental scale. The closed circles in graph A represent the actual measured growth rates. For comparison, the thin line in graph A simulates a strict allometric growth pattern. Fat pads and whole body lipids are presented in graph B. Vertical lines represent the standard deviation; numbers indicate sample sizes.

conditions. The threshold body length at metamorphosis lies between 10 and $11 \mathrm{~mm}$.

Metamorphic strategies and energy allocation at different tadpole densities. - Tadpoles reared at high density (HD) stay significantly longer $(P<0.001$; ANOVA) in the larval phase compared with conspecifics raised at low density (Table 1 ). The body lengths attained at metamorphosis are giv-
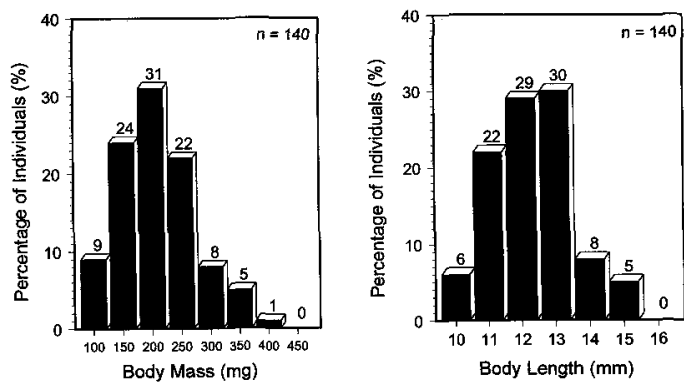

Fig. 2. Range of body mass and body length at metamorphosis of Hyperolius marmoratus taeniatus froglets raised under various breeding densities (between five and 20 tadpoles per liter).

en in Figure 3A-B. Mean body length differed significantly between both groups (Table 1; $P$ $<0.01$; ANOVA), and 14 out of the $47 \mathrm{LD}$ froglets surpassed the maximum body length of the HD froglets. At LD, diversity in body length at metamorphosis was significantly higher $(P<$ 0.01; Kolmogoroff-Smirnoff test) than under HD (Fig. 3A-B). Usually, froglets that metamorphosed earlier had a smaller body length. LD froglets that metamorphosed with a body length between 11 and $14 \mathrm{~mm}$ showed a significantly higher number of individuals with a larger body lipid content $(P<0.05$; U-Test $)$ than did HD froglets that had attained a comparable metamorphic body length (11.5-13 $\mathrm{mm})$. Froglets from LD groups reached total body lipid values up to $23.5 \%$ of the body dry mass (Fig. 3C), whereas, in the HD groups, the maximum body lipid was $19.5 \%$.

Up to stage 42, survival during the larval development was unaffected by tadpole density (Fig. 4). Starting from stage 42 (onset of metamorphic climax), the mortality greatly increased and was almost doubled in HD populations compared with LD groups. The low percentage $(62 \%)$ of successful metamorphoses in the HD groups is due to the high mortality, especially of the smaller sized animals. This may explain the lack of this size class under HD conditions (Fig. 3B).

Table 1. Length of the larval Period and Body Size at Metamorphosis of the Reedfroc Hyperolius marmoratus taeniatus Related to the TADPole Density DURING the Larval Stage.

\begin{tabular}{lccc}
\hline \multicolumn{1}{c}{ Test parameter } & 20 Ind./Group & 60 Ind./Group & $\begin{array}{c}\text { Significance } \\
(\text { ANOVA); } P<\end{array}$ \\
\hline No. of replicates & 3 & 2 & - \\
Length of the larval period & $46.5 \pm 10.2 \mathrm{~d}$ & $63.0 \pm 10.5 \mathrm{~d}$ & 0.001 \\
No. of froglets & 47 & 74 & 0.001 \\
Body length at metamorphosis & $12.8 \pm 1.5 \mathrm{~mm}$ & $12.3 \pm 0.7 \mathrm{~mm}$ & 0.01 \\
\hline
\end{tabular}



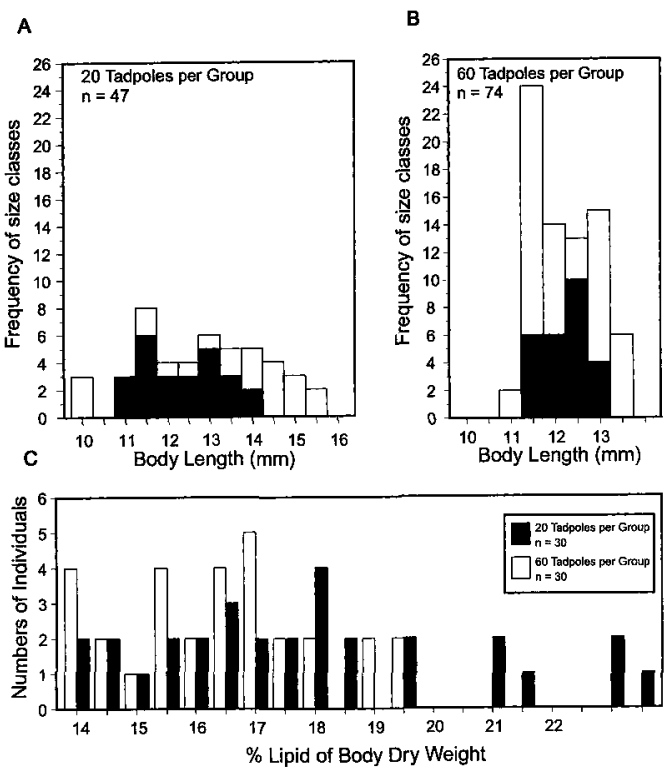

Fig. 3. Body length of freshly metamorphosed $H y$ perolius marmoratus taeniatus which were raised under low (four tadpoles/liter $=3 \mathrm{~A}$ ) and high (12 tadpoles/ liter $=3$ B) tadpole density. Bright columns represent all froglets that had successfully metamorphosed ( $\mathrm{n}$ $=\mathbf{4 7}$ for $\mathbf{2 0}$ tadpoles/group, $\mathrm{n}=\mathbf{7 4}$ for 60 tadpoles/ group), dark columns show body lengths of those froglets of which body lipid contents were analyzed (C). For analysis of total body lipid, froglets of comparable body length from both treatment groups were selected $(\mathrm{C})$.

Nitrogen excretion pattern in relation to the ambient ammonia concentration.-During periods of regular precipitation, a natal pond of native toads (B. bufo) showed an osmotic concentration of less than $20 \mathrm{mOsm} / \mathrm{kg}$ (five measurements between May and July). Even after passing a period of extreme dryness (whereby evaporation caused about $70 \%$ loss of the initial volume), a small pond, occupied by Bufo tadpoles, exhibited osmotic concentrations of only $57 \mathrm{mOsm}$ at maximum (five measurements after four weeks without precipitation). Natal ponds of $H$. v. nitidulus (five pools measured in the Comoe' National Park in the northern Ivory Coast) revealed a very low conductivity suggesting that evaporation exerts a comparably minor effect on the osmotic concentration. In contrast, because of occasional rainfalls, evaporation, excretion, and, above all, microbial degradation, the ammonia concentration of such small water ponds undergoes dramatic fluctuations and temporarily exceeded $20 \mathrm{mg} \mathrm{NH}_{4}{ }^{+}-\mathrm{N} /$ liter. The ammonia concentration of the examined $B$ ufo pond water raised from less than $0.1 \mathrm{mg}$ to $3.36 \mathrm{mg} \mathrm{NH}{ }_{4}^{+}-\mathrm{N} /$ liter in approximately a

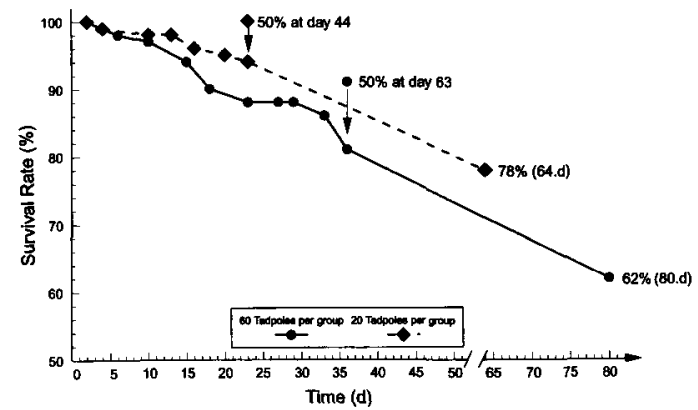

Fig. 4. Survival rate of Hyperolius marmoratus taeniatus tadpoles related to tadpole density. At day 0 , all tadpoles had reached stage 23 (according to Gosner, 1960). Arrows indicate time of first metamorphosis; in addition, for each treatment, the day is indicated when $50 \%$ of all individuals had successfully metamorphosed. Both events occurred earlier in groups with lower tadpole density. Figure 4 represents survival rate of combined replicates ( $n=60$ for 20/ tadpoles/group and $\mathrm{n}=120$ for 60 tadpoles/group). Numbers at curve ends refer to the percent of all successfully metamorphosed froglets of each experimental group and the day of last metamorphosis.

four-week dry period. Ammonia concentrations up to $7.82 \mathrm{mg} \mathrm{NH}_{4}{ }^{+}-\mathrm{N} /$ liter were recorded in our mass breeding containers of $H$. v. ommatostictus and $H$. m. taeniatus (15-25 larvae/liter). At 10-20 larvae/liter, this ammonia level was achieved within three to four days after water refreshing.

Which physiological mechanisms contribute to the tolerance of high ammonia concentrations? - In densely populated breeding containers ( $>20$ larvae/ liter), high mortality rates occurred if water was not regularly changed (each second or third day). From all parameters determined $\left(\mathrm{O}_{2}\right.$-content, temperature, overall osmotic and ammonia concentration), the ammonia concentration revealed the highest fluctuations. Since, in the mass breeding, a large number of casualties could be observed at an ammonia level of just a little more than $8 \mathrm{mg} \mathrm{NH}_{4}{ }^{+}-\mathrm{N} /$ liter $(14$ observations at a breeding density of 10-25 larvae/liter), we expected some physiological mechanisms which may counteract a critical ammonia level within the body fluid, for example by an induction/activity increase of the ornithine cycle.)

At ammonia concentrations of less than $1 \mathrm{mg}$ / liter, only very small amounts of urea were excreted by premetamorphic stages of $H . v . \mathrm{om}$ matostictus and $B$. bufo (Fig. 5). The values for $H$. $m$. taeniatus were under the lowest detection limit $\left(0.83 \mathrm{ug} \cdot \mathrm{g}^{-1} \cdot \mathrm{h}^{-1}\right)$. This was also true for the urea concentration in the body fluids 

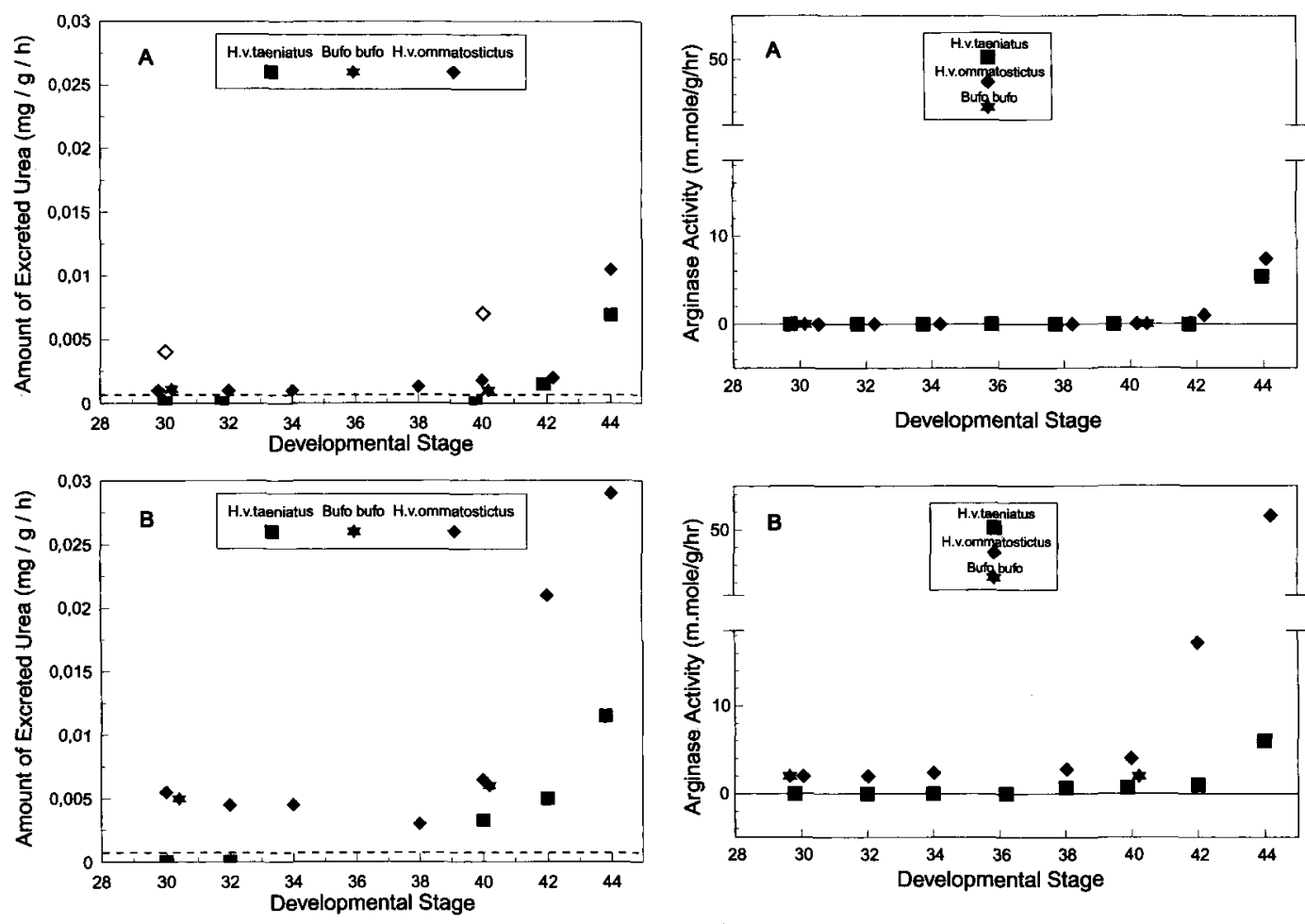

Fig. 5. Amount of urea excreted by Bufo and $H y$ perolius spp. tadpoles which were raised (a) at low ambient ammonia concentration ( $\leq 1 \mathrm{mg} \mathrm{NH}_{4}{ }^{+}-\mathrm{N}$ ) liter; A, black symbols), (b) at high ambient ammonia concentration (approximately $5 \mathrm{mg} \mathrm{NH}_{4}{ }^{+}-\mathrm{N}$ /liter, $B$, black symbols), (c) for two days in tap water to which $5 \mathrm{mg} \mathrm{NH}{ }_{4}^{+}-\mathrm{N}$ /liter had been added ( $\mathrm{A}$, white symbols). Dotted line indicates the lower detection limit for urea analysis $\left(0.83 \mathrm{ug} \cdot \mathrm{g}^{-1} \cdot \mathrm{h}^{-1}\right)$. Developmental stages are numbered according to Gosner (1960). Each symbol represents the mean of three replicates.

(not shown in Fig. 5). At the beginning of the metamorphic climax (stage 42), a strong increase in urea excretion took place in both $\mathrm{Hy}$ perolius species (Bufo was not examined). Shortly before the froglets left the natal pond (stage 44 ), the mode of excretion shifted from ammonotelism to ureotelism. The arginase activity increased in a comparable fashion (Fig. 6).

At high ambient ammonia concentrations $\left(\mathrm{NH}_{4}{ }^{+}-\mathrm{N}\right.$ concentration approximately $5 \mathrm{mg}$ $\mathrm{NH}_{4}{ }^{+}-\mathrm{N} /$ liter), early developmental stages of $B$. bufo and $H$. $v$. ommatostictus synthesized and excreted urea well above the detection limit (Figs. 5-6). On the other hand, the urea excretion rate of the premetamorphic stages of the related species $H$. m. taeniatus were always below the detection limit even when the ammonia concentration of the pond water approximated 5 $\mathrm{mg} \mathrm{NH}_{4}{ }^{+}-\mathrm{N} /$ liter. Only at the end of pro-

Fig. 6. Changes in the hepatic arginase activity of $B u f o$ and Hyperolius spp. tadpoles raised in water with different ammonia concentrations. For explanation of symbols see Figure 5 .

metamorphosis, traces of urea were detected at high ambient ammonia concentrations. The plasma urea content of all three species, however, remained below the detection limit until stage 42 , irrespective of the ambient ammonia concentration.

If $H$. $v$. ommatostictus tadpoles were exposed to fresh tap water into which $5 \mathrm{mg} \mathrm{NH}_{4}{ }^{+}-\mathrm{N}$ / liter was added, they also responded with an increased urea excretion rate (Fig. 5). In contrast, larvae of the same natal container which were reared in ammonia-free tap water under otherwise identical conditions, exhibited an excretion rate close to the detection limit $(0.9 \mathrm{ug}$ $\left.\cdot \mathrm{g}^{-1} \cdot \mathrm{h}^{-1}\right)$. This indicates that the activity level of the ornithine cycle is regulated in relation to the ammonia concentration of the natal pond water.

Effect of water deterioration on the physiological adjustment at metamorphosis.- Under wet season conditions, regular rainfalls provide a fairly constant water quality within temporary ponds. Under transitional conditions, however, water quality changes rapidly (KEL, unpubl.) which may signal to tadpoles the onset of dry period 
conditions. An appropriate physiological adjustment at metamorphosis would yield tremendous benefits by greatly improving growth and hence the survival chances of the froglets. Figure $7 \mathrm{a}$ and $7 \mathrm{~b}_{2}$ demonstrate that freshly metamorphosed froglets [mean body length (a): $\left.12.6 \pm 0.9 \mathrm{~mm} ;\left(b_{2}\right): 12.9 \pm 1.2 \mathrm{~mm}\right]$, which were raised in aquaria with high ammonia levels (low water exchange rate) during the larval period, exhibited mortality rates of less than 15\% during a three-week observation period when kept under the more adverse climatic conditions that prevail during the transition from wet to dry season. These froglets were sitting on leaflets well exposed to incident radiation and exhibited a high foraging activity. In contrast, froglets that developed in breeding waters with low ammonia levels (high water exchange rate) suffered from a highly increased mortality rate of $40 \%$ and more (Fig. $7 b_{1}$ ) under identical postmetamorphic rearing conditions. These differences in survival rate were not attributed to significantly different body lengths at metamorphosis compared with treatment group A [mean body length $\left(b_{1}\right): 12.4 \pm 0.8 \mathrm{~mm}$ ]. For most of the time, these froglets crept under clay pots in the bottom of the terraria or into soil crevices. This behavior, which was generally not observed in either of the other two treatment groups, was also unchanged at reduced air temperature. Only after repeated capturings, waterings, and solitary maintenance in small containers at an air humidity near $80-90 \%$ did these froglets recuperate and become gradually acclimatized to the transitional conditions.

These behavioral differences are fully consistent with observations made on freshly metamorphosed froglets in the field. Froglets that metamorphosed under wet season conditions differ considerably from froglets metamorphosing during the transitional period between the wet and dry season in, for example, their daytime resting behavior, among others. Although the latter prefer exposed positions on vegetation between 0.5 and $2.0 \mathrm{~m}$ above ground, the former behave crepuscular, searching for humid shelters in dense vegetation near to or on the ground (KEL, unpubl.).

How important is larval adjustment to transitional climatic conditions in the field?-Until now, we could only collect corresponding data of the West African species $H$. $v$. nitidulus (KEL, unpubl.). In its community of about 30 anurans, this species belongs (together with $H$. nasutus, to some extent also Afrixalus fulvorittatus) to the small group that breeds very late in the season. Depending on the rain fall pattern in the respective year a third to well over half of all
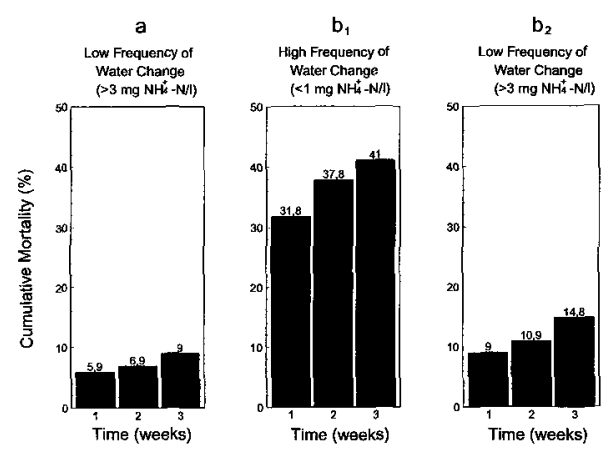

Fig. 7. Survival rates of freshly metamorphosed Hyperolius viridiflarus ommatostictus froglets under harsh climatic conditions (low air humidity, high temperature, low irrigation rate) in relation to the ammonia concentration of the natal pond as encountered during the larval period. Tadpoles from two egg batches of approximately $150 \mathrm{eggs}$ each were raised at a continuously high ammonia concentration until metamorphosis (7a). Six comparably large egg batches were kept at low ammonia concentrations until $50 \%$ of the froglets had metamorphosed $\left(7 b_{1}\right)$. Afterward, tadpoles were maintained under conditions as described for $7 \mathrm{a}\left(7 \mathrm{~b}_{2}\right)$. The cumulative mortality refers to 160 froglets for each set of conditions which were placed in subgroups of 80 froglets in 200-liter terraria.

clutches that $H$. v. nitidulus produced were laid during the last four weeks of the rainy season (which usually ends at the end of Sept.) and during the following four to six weeks (KEL, unpubl.). Since larval development requires at the very least six weeks, a large proportion of all tadpoles will metamorphose under transient conditions with many weeks of constantly shrinking water bodies. We assume that, by far, most of the aestivating juveniles belong to those that have experienced these transient conditions and display high tolerance toward thermal and drought stress already immediately upon their metamorphosis. [Frogs from early clutches seem to often follow a different route of direct development, achieving maturity during their natal rainy season, being then unable to aestivate (see also Geise, 1987; Grafe and Linsenmair, 1989)].

\section{Discussion}

Metamorphic strategies in relation to intraspecific crowding.-To achieve access to different profitable nutritional resources, various lifecycle strategies have been evolved. The complex life cycle of anurans is especially spectacular, among other reasons, because of the change from the aquatic to the terrestrial mode of life which is 
associated with a fundamental shift in nutrition from a mostly herbivorous to a fully carnivorous diet (Feder and Burggren, 1992).

The high primary productivity of many temporary ponds offers a rich nutritional resource allowing high rates of secondary productivity. However, in small temporary ponds, abiotic factors are often highly fluctuating, therefore often being life threatening for the inhabitants, and at best directly or indirectly delay growth and differentiation (i.e., Cummins, 1989). Growth and differentiation rates can also be greatly affected by intra- and interspecific competition (Hota and Dash, 1981; Semlitsch, 1987; Cummins, 1989), since extreme population densities are quite common in ephemeral ponds. Alford and Harris (1988) demonstrated that growth, and hence differentiation rates, respond to alterations in food availability that occur at any point during the larval period. However, before food competition causes negative effects, it seems that "social stress" becomes decisive (Adolph, 1931; Alford and Crump, 1982). Gromko et al. (1973) and John and Fenster (1975) assumed that behavioral interactions and their influence on the hormonal control of growth account for the crowding effect. For a wide spectrum of anurans, unfavorable growth conditions like an increased physical harshness (Warner et al. 1991), a restriction in food supply (Hota and Dash, 1981; Semlitsch, 1987; Alford and Harris, 1988), or an increased population density (Dash and Hota, 1980; Pandian and Marian, 1985; Warner et al., 1991) cause slower growth rates, a delay of metamorphosis, and a reduction in transformation size (Wilbur and Collins, 1973). In agreement with the findings on other anurans (Wilbur, 1977; Crump, 1981; Warner et al., 1991), Hyperolius reached its maximum body length at metamorphosis only at lower levels of intraspecific crowding (LD). However, tadpoles raised under LD revealed a significantly higher diversity of body length at metamorphosis than those reared under HD. This indicates that unfavorable growth conditions force most tadpoles to leave their natal pond shortly after reaching a threshold size. The lack of the smallest observed size classes at HD might be a result of a size-biased mortality. The higher diversity of body lengths at metamorphosis under LD conditions points to the existence of differing metamorphic strategies. Kaplan and Cooper (1984) showed that, in a variable unpredictable environment, from the parent animals' viewpoint, a reproductive pattern can stabilize in which only some of the offspring are optimally adapted to the actual conditions ahead. This could explain why a pro- portion of individuals undergo their metamorphosis at a small body length in spite of favorable growth conditions in the aquatic environment. A rapid metamorphosis may be advantageous if the risk of predation in the natal pond is generally high, or alters in relation to size with an increasing susceptibility to predators at larger body sizes, or if the terrestrial habitat offers better conditions in terms of net production rates. Moreover, it appears to be a good strategy against unforeseeable and rapidly changing climatic conditions. Metamorphosing at a larger body length can increase the survival of terrestrial juveniles and allow a bivoltine life cycle if metamorphosis occurs within the wet season (Geise, 1987; see also Grafe and Linsenmair, 1989).

Whether a choice between these different options is possible depends strongly upon the abiotic and biotic quality of the aquatic habitat. Under unfavorable aquatic life conditions, tadpoles should metamorphose as soon as possible increasing the chance to encounter nutritionally favorable conditions in the terrestrial habitat (before the onset of the dry period). However, the animals can only start metamorphosis after passing a threshold body length (Wilbur and Collins, 1973) and having accumulated a minimum of fat reserves (Crump, 1981).

Physiological constraints during the larval period.To survive under the highly variable and unpredictably changing conditions of small natal ponds, the inhabitants must have developed either a great tolerance or a series of physiological adaptations to counteract the strong environmental fluctuations (e.g., temperature, $\mathrm{pH}$, oxygen partial pressure, metabolic waste products). In the examined temporary ponds, evaporation hardly affected the total osmolarity of the aquatic environment. However, we found a considerable accumulation of nitrogenous waste products. Under natural conditions, the ammonia concentration of small ponds increased during a period of low precipitation to approximately $4 \mathrm{mg} \mathrm{NH}_{4}{ }^{+}-\mathrm{N} /$ liter, which is already an acute toxic level for most fish (Thomas et al., 1976). In temporary ponds in West Africa, more than $20 \mathrm{mg} \mathrm{NH}_{4}^{+}-\mathrm{N}$ /liter were measured. Ammonia tolerances in amphibians are not well documented. From our work under laboratory conditions, the tolerance limit for the investigated species appeared to be close to $8 \mathrm{mg} \mathrm{NH}{ }_{4}^{+}-\mathrm{N} /$ liter. Fromm and Gillette (1968) found that the rainbow trout increased the rate of the ammonia consuming amino acid synthesis as a physiological response to an uprising ammonia concentration in the ambient 
water. The resulting amino acids were assumed to be subsequently eliminated via the urine. Tadpoles of $B$. bufo and $H$. v. ommatostictus showed a physiologically comparable response which was also found for anurans that face periods of water restriction during their larval development (i.e., development in foam nests; Shoemaker and McClanahan 1973). If the ammonia level of the natal pond increased, Bufo and Hyperolius responded with an activity increase of the ammonia-consuming ornithine cycle which apparently serves to prevent a further accumulation of the cell-toxic ammonia in the body fluid. This physiological response mechanism, however, varied among the examined species and was related to the developmental stage and to the acclimatization conditions. Hyperolius marmoratus taeniatus did not show this physiological response until the end of prometamorphosis. Nevertheless, it survived in ammonia-contaminated water as well as $H$. $v$. ommatostictus. This species may have developed a high tolerance to low blood $\mathrm{pH}$ values, as described for Rana temporaria and Rana catesbeiana tadpoles (Candelas and Gomery, 1963; Harpur, 1968). Because of its high diffusion capacity, $\mathrm{NH}_{3}$ contributes much more to the cell-toxic effects of ammonia than does $\mathrm{NH}_{4}{ }^{+}$. A decrease of the blood $\mathrm{pH}$ value would result in a decrease of the $\mathrm{NH}_{3}$ concentration in favor of $\mathrm{NH}_{4}{ }^{+}$.

Effect of water deterioration on the physiological adjustments at metamorphosis.-Pough and Kamel (1984) assumed that freshly metamorphosed froglets of anuran species with relatively short larval periods and small body sizes at metamorphosis are more vulnerable to adverse climatic conditions than are species with long larval periods and large metamorphic body sizes. According to these authors, species with a smaller body size at metamorphosis-Hyperolius would belong in this group-have to undergo larger physiological changes after their metamorphosis to adjust properly to the conditions of the terrestrial environment. At metamorphosis, most Hyperolius froglets do not meet the threshold body size and minimum energy stores which are required for surviving the forthcoming dry season (Geise, 1987). Therefore, they rapidly have to achieve an effective access to the nutritional resources of the terrestrial habitat. A few days more or less with proper conditions for food uptake in the terrestrial habitat might be decisive for survival of the dry period (Schmuck et al., 1988). If wet season conditions prevail at metamorphosis, a longer lasting, more extensive postmetamorphic adjustment to terrestriality may not be prohibitive for acquiring enough energy stores before onset of the dry season. Metamorphosis closer to the dry season, however, would force froglets to start immediately with food uptake which, in turn, requires an appropriate physiological adjustment to the prevailing climatic conditions in the terrestrial habitat. In the present study, it has been shown that a deterioration of the pond water quality, as indicated by an accumulation of nitrogenous waste products, can provide signals which in $H . v$. ommatostictus tadpoles induce physiological adjustments to harsher climatic conditions at metamorphosis. The activity increase of the ornithine cycle as a response to an increased ambient ammonia concentration may subsequently cause these froglets to adjust physiologically to dry period conditions. In contrast, during periods of regular rainfalls, the concentration of nitrogenous wastes is assumed to be low in the natal ponds. Froglets raised from tadpoles that developed in regularly refreshed water proved to be poorly adapted to transient conditions with restricted water availability, with high temperatures and low air humidity during day time. These froglets spent most of the time in moist soil cervices and only rarely displayed any foraging behavior. The depressed foraging activity was considered to be associated with a higher evaporative water loss. As Preest and Pough (1989) showed for B. americanus, dehydration can strongly decrease the locomotory performance of anurans.

Obviously, many questions still remain unanswered. Which spectrum of physiological stresses is a tadpole subjected to during its adaptation to harsh climatic conditions and what are the physiological/energetic costs for the adjustment? What are the threshold concentrations? For reedfrogs, the minimum ammonia concentration may lie somewhere between 3 and $5 \mathrm{mg} \mathrm{NH}{ }_{4}^{+}-\mathrm{N} /$ liter. How is this physiological response regulated? Can tadpoles discriminate between a climate- and a density-dependent accumulation of nitrogenous wastes? It is likely that fluctuations of additional factors that are mainly determined by climatic conditions facilitate such a discrimination. In any case, we have to be aware that such a mechanism presumably does not depend on a single factor but that it is controlled by a complex of quantitative and qualitative changes in the ecological conditions of the aquatic environment.

\section{ACKNOWLEDGMENTS}

We thank M. Grey for amending the language and T. Riebschläger for his assistance in performing the drawings. This work was sup- 
ported by the Deutsche Forschungsgemeinschaft, grant Li 150/ii-i,2 and SFB 253, and by the Volkswagen-Stiftung (AZ I/ 64 102). We thank the Ministre des Eaux et Forets and the Ministre de la Recherche Scientifique, Republique de Cote d'Ivoire for granting the research permit for doing fieldwork in the Parc National de la Comoe'.

\section{Literature Gited}

Adolph, E. F. 1931. The size of the body and the size of the environment in the growth of tadpoles. Biol. Bull. 61:350-375.

Alford, R. A., And M. L. Crump. 1982. Habitat partitioning size classes of larval southern leopard frogs, Rana utricularia. Copeia 1982:367-373.

$\longrightarrow$, AND R. N. HARRIs. 1988. Effects of larval growth history on anuran metamorphosis. Amer. Nat. 131:91-106.

Berven, K. A., and B. G. Chadra. 1988. The relationship among egg size, density and food level on larval development in the wood frog (Rana sylvatica). Oecologia 75:67-72.

Beurden, E. K. Van. 1980. Energy metabolism of dormant Australian water holding frogs (Cyclorana platycephalus). Copeia 1980:787-799.

BrockelmanN, W. Y. 1969. Analysis of density effects and predation in Bufo americanus tadpoles. Ecology 50:632-644.

Candelas, C., AND M. Gomez. 1963. Nitrogen excretion in tadpoles of Leptodactylus albilabrus and Rana catesbeiana. Amer. Zool. 3:521-522.

Crump, M. L. 1981. Energy accumulation and amphibian metamorphosis. Oecologia 49:167-169.

Cummins, C. P. 1989. Interaction between the effects of $\mathrm{pH}$ and density on growth and development in Rana temporaria L. tadpoles. Functional Ecology 3:45-52.

Dash, M. C., AND A. K. HotA. 1980. Density effects on the survival, growth rate, and metamorphosis of Rana tigrina tadpoles. Ecology 6:1025-1028.

Duellman, W. E., AND L. Trueb. 1986. Biology of amphibians. McGraw-Hill Book Company, New York, New York.

Feder, M. E., AND W. W. Burggren. 1992. Environmental physiology of the amphibians. Univ. of Chicago Press. Chicago, Illinois; London, England.

Fromm, P. O., and J. R. Gillette. 1968. Effect of ambient ammonia on blood ammonia and nitrogen excretion of rainbow trout (Salmo gairdneri). Comp. Biochem. Physiol. 26:887-896.

GEISE, W. 1987. Leben unter extrembedingungen: untersuchungen zur Ästivationsphysiologie und zur variabilität im lebenszyklus beim Afrikanischen riedfrosch Hyperolius viridiflavus (Anura: Hyperoliidae). Unpubl. Ph.D. diss., Bayerische Lulius-Maximilians-Universität, Würzburg, Germany.

- AND K. E. LinsenMair. 1988. Adaptations of the reed frog Hyperolius viridiflavus (Amphibia, Anura, Hyperoliidae) to its arid environment. IV. Ecological significance of water economy with com- ments on thermoregulation and energy allocation. Oecologia 77:327-338.

GosNer, K. L. 1960. A simplified table for staging anuran embryos and larvae with notes on identification. Herpetologica 16:183-190.

Grafe, T. U., And K. E. Linsenmair. 1989. Protogynous sex change in the reed frog Hyperolius viridiflavus. Copeia 1989:1024-1029.

Gromko, M. H., F. S. Mason, and S. J. Smith-Gill. 1973. Analysis of the crowding effect in Rana pipiens tadpoles. J. Exp. Zool. 186:63-72.

HaRpur, R. P. 1968. Osmoregulation et metabolisme de l'uree: comparaison entre Bufo viridis et Rana temporaria. Can. J. Zool. 46:295-301.

HochachKa, P. W., ANd G. N. Somero. 1980. Strategien biochemischer Anpassung. Georg Thieme Verlag, Stuttgart, Germany; New York, New York.

Hota, A. K., AND M. C. DASH. 1981. Growth and metamorphosis of Rana tigrina larvae: effects of food level and larval density. OIKOS 37:349-352.

John, K. R., AND D. Fenster. 1975. The effects of partitions on the growth rate of crowded Rana pipiens tadpoles. Amer. Mid. Nat. 93:123-130.

Kaplan, R. H., AND W. S. CoOPER. 1984. The evolution of developmental plasticity in reproductive characteristics: an application of the "adaptive coin flipping" principle. Amer. Nat. 123:393-410.

Kobelt, F., And K. E. Linsenmair. 1992. Adaptations of the reed frog Hyperolius viridiflavus (Amphibia: Anura: Hyperoliidae) to its arid environment. VI. The iridophores in the skin as radiation reflectors. J. Comp. Physiol. B 162:314-326.

Low, B. S. 1976. The evolution of amphibian life histories in the desert, p. 149-195. In: Evolution of desert biota. D. W. Goodall (ed.). Univ. of Texas Press, Austin.

Pandian, T. J., And M. P. Marian. 1985. Predicting anuran metamorphosis and energetics. Physiol. Zool. 23:538-552.

Pough, F. H., AND S. Kamel. 1984. Post-metamorphic change in activity metabolism of anurans in relation to life history. Oecologia 65:138-144.

Preest, M. R., AND F. H. Pough. 1989. Interaction of temperature and hydration on locomotion of toads. Functional Ecology 3:693-699.

Schiotz, A. 1967. The treefrogs (Rhacophoridae) of West Africa. Spolia Zoologie Musei Hauniensis 25 Kopenhagen, Denmark.

Schmuck, R., AND K. E. Linsenmair. 1988. Adaptations of the reed frog Hyperolius viridiflavus (Amphibia, Anura, Hyperoliidae) to its arid environment. III. Aspects of nitrogen metabolism and osmoregulation in the reed frog, Hyperolius viridiflavus taeniatus, with special reference to the role of iridophores. Oecologica 75:354-361.

-, F. Kobelt, and K. E. Linsenmair. 1988. Adaptations of the reed frog Hyperolius viridiflavus (Amphibia, Anura, Hyperoliidae) to its arid environment. V. Iridophores and nitrogen metabolism. J. Comp. Physiol. 158:537-546.

SEMlitsch, R. D. 1987. Paedomorphosis in Ambystoma talpoideum: effects of density, food, and pond drying. Ecology 68:994-1002.

Shoemaker, V. H., and L. L. McClanahan. 1973. 
Nitrogen excretion in the larvae of a land-nesting frog (Leptodactylus bufonius). Comp. Biochem. Physiol. 44A:1149-1156.

Smith-Gill, S. J., ANd K. A. Berven. 1979. Predicting amphibian metamorphosis. Amer. Nat. 113: 563-585.

Thomas, J. D., M. Powles, and R. Lodge. 1976. The chemical ecology of Biomphalaria glabrata: the effects of ammonia to the growth rate of juvenile snails. Biol. Bull. 151:386-397.

Warner, S. C., W. A. Dunson, and J. Travis. 1991. Interaction of $\mathrm{pH}$, density, and priority effects on the survivorship and growth of two species of hylid tadpoles. Oecologia 88:331-339.

WASSERSUG, R. J. 1975. The adaptive significance of the tadpole stage with comments on the maintenance of complex life cycles in anurans. Amer. Zool. 15:405-417.

Werner, E. E. 1986. Amphibian metamorphosis: growth rate, predation risk, and the optimal size at transformation. Amer. Nat. 128:319-341.

WILBuR, H. M. 1977. Density dependent aspects of growth and metamorphosis in Bufo americanus. Ecology 58:196-200.

1980. Complex life cycles. Ann. Rev. Ecol. Syst. 11:67-93.

, AND J. P. Collins. 1973. Ecological aspects of amphibian metamorphosis. Science 182:13051314.

THEODOR-BOVERI-INSTITUT Für BIOWISSENSCHAFTEN, LEHRSTUHL FÜr TIERÖKOLOGIE UND TROPENBIOLOGIE, Biozentrum, Am Hubland, D-97074 Würzburg, Germany. Submitted: $9 \mathrm{Feb}$. 1993. Accepted: 29 Oct. 1993. Section editor: G. R. Ultsch. 